\title{
Ductular reaction, cytokeratin 7 positivity, and gamma-glutamyl transferase in multistage hepatocarcinogenesis in...
}

Article in Protoplasma · August 2016

DOI: $10.1007 /$ s00709-016-1000-0

CITATIONS

0

10 authors, including:

\section{Andrea Janz Moreira}

Rede Metodista de Educação do Sul

10 PUBLICATIONS 389 CITATIONS

SEE PROFILE

\section{Jorge Luiz Dos santos}

Universidade Federal do Rio Grande do Sul 27 PUBLICATIONS 200 CITATIONS

SEE PROFILE
READS

19

Silvia Bona

Universidade Federal do Rio Grande do Sul 19 PUBLICATIONS 158 CITATIONS

SEE PROFILE

Norma Possa Marroni

Universidade Federal do Rio Grande do Sul 144 PUBLICATIONS 2,277 CITATIONS

SEE PROFILE 


\title{
Ductular reaction, cytokeratin 7 positivity, and gamma-glutamyl transferase in multistage hepatocarcinogenesis in rats
}

\author{
Andrea Janz Moreira ${ }^{1,2,3} \cdot$ Graziella Ramos Rodrigues $^{4} \cdot$ Silvia Bona $^{1}$ • \\ Leila Xavier Sinigaglia Fratta ${ }^{1}$ - Giovana Regina Weber ${ }^{1}$. \\ Jaqueline Nascimento Picada ${ }^{5}$. Jorge Luiz dos Santos ${ }^{1,6}$ • Carlos Thadeu Cerski ${ }^{7}$. \\ Claudio Augusto Marroni ${ }^{8}$ - Norma Possa Marroni ${ }^{1,2,5,9}$
}

Received: 31 October 2015 / Accepted: 22 June 2016

(C) Springer-Verlag Wien 2016

\begin{abstract}
Hepatocellular carcinoma (HCC) is the most common primary malignancy of the liver and is characterized by multistage formation. The presence of ductular reaction, cytokeratin 7 positivity (PCK7), and increased levels of gamma glutamyltransferase ( $\gamma \mathrm{GT})$ has been observed during liver carcinogenesis and contribute to tumor progression. Our goal was to evaluate the ductular reaction in multistage carcinogenesis and to correlate PCK7 and $\gamma$ GT levels with tumor incidence, histological characteristics, liver DNA damage index, and the expression of oxidative stress proteins. HCC was induced in 24 male Wistar rats weighing $145-150 \mathrm{~g}$ by chronic and intermittent exposure to 50 or $100 \mathrm{mg} / \mathrm{kg}$ diethylnitrosamine (DEN). Six control animals received only vehicle. Blood was collected to determine hepatic enzyme levels. Animals were divided into three groups: control (CO), precancerous lesions (PL), and advanced HCC. Liver samples were obtained for immunohistochemical analyses and the
\end{abstract}

Handling Editor: Christos D. Katsetos

Norma Possa Marroni

normap.marroni@gmail.com; nmarroni@terra.com.br

1 Center of Experimental Research, Hospital de Clínicas de Porto Alegre, Rua Ramiro Barcelos, 2400, Porto Alegre, RS, Brazil

2 Department of Biological Sciences: Physiology, Universidade Federal do Rio Grande do Sul, Rua Sarmento Leite, 500, Porto Alegre, RS, Brazil

3 Department of Physical Therapy of Porto Alegre Institute, IPA, Rua Joaquim Pedro Salgado, 80, Porto Alegre, Brazil

4 Gene Therapy Center, Center of Experimental Research, Hospital de Clínicas de Porto Alegre, Rua Ramiro Barcelos, 2400,

Porto Alegre, Brazil measurement of protein expression. Statistical analyses included Tukey's test and Pearson's correlation analyses. We observed an extensive ductular reaction in advanced $\mathrm{HCC}$ and a strong correlation between PCK7 and levels of $\gamma \mathrm{GT}$ and the poor prognosis and aggressiveness of HCC. The extent of PCK7 and high $\gamma$ GT levels were associated with overexpression of inducible nitric oxide synthase (iNOS) and heat shock factor protein 1 (HSF-1). However, PCK7 and $\gamma \mathrm{GT}$ levels were negatively correlated with protein expression of nuclear factor erythroid 2-related factor 2 (NRF2) and inducible heat shock protein 70 (iHSP70). These findings suggest that ductular reaction is involved in the progression of multistage hepatocarcinogenesis.

Keywords Hepatocellular carcinoma · Diethylnitrosamine · Gamma-glutamyl transferase
5 Program in Cell and Molecular Biology Applied to Health, Universidade Luterana do Brasil, Av. Farroupilha, 8001, Canoas, Brazil

6 Pediatric Hepatology Unit, Hospital de Clínicas de Porto Alegre, Rua Ramiro Barcelos, 2400, Porto Alegre, Brazil

7 Department of Pathology, School of Medicine, Universidade Federal do Rio Grande do Sul, Porto Alegre, RS, Brazil

8 Program in Liver Diseases, Universidade Federal de Ciências da Saúde de Porto Alegre, Rua Sarmento Leite, 245, Porto Alegre, Brazil

9 Rua José Kanan Aranha 102, 91760-470 Porto Alegre, RS, Brazil 


\section{Introduction}

Hepatocellular carcinoma (HCC), the most common primary malignancy of the liver, is observed as a complication of chronic liver disease. HCC is the fifth most common tumor worldwide, with over 700,000 new cases per year (Ferlay et al. 2010). Chronic inflammatory liver diseases are favorable conditions for the development of hepatocellular carcinoma (HCC) and include the following: steatosis, steatohepatitis, alcoholic cirrhosis, cirrhosis due to hepatitis B and C (HBV and HCV), $\alpha 1$-antitrypsin deficiency, hemochromatosis, and tyrosinemia. In HCV-positive patients, for example, HCC developed 30 years on average after the contamination and almost exclusively in cirrhotic patients (Bruix et al. 2004).

The HCC formation process is extremely complex. To seek effective therapies, it is necessary to establish the differences between normal liver tissue, precancerous lesion, and advanced HCC. Numerous studies demonstrate that ductular reaction is a risk factor for cancer (Guiu et al. 2012; Desmet 2011) and that cytokeratin (CK) and enzyme gamma-glutamyl transferase ( $\gamma$ GT) (Roomi et al. 1987) may be altered in cancers. The ability of tumor cells of hepatocellular origin to express a biliary cytokeratin profile may contribute to the very high levels of $\gamma$ GT in HCC (Van Eyken et al. 1988; Gould 1986). Cholangiocytes and liver progenitor cells express CK7 and CK19, but this is not observed in normal hepatocytes. However, CK7 expression is elevated in the presence of HCC (Durnez et al. 2006).

The liver enzyme gamma-glutamyl transferase $(\gamma \mathrm{GT})$ is considered a tumor marker in several cancers (Whitfield 2001; Pompella et al. 2006; Paolicchi et al. 1996). Overexpressed $\gamma \mathrm{GT}$ is believed to influence the balance between proliferation and apoptosis and thus between tumor progression and regression. Many studies involving the exposure of animals to carcinogenic chemical agents have reported increased levels of serum $\gamma$ GT (Pompella et al. 2006; Zhang et al. 2006).

In liver disease, both animal (Zhang et al. 2006) and epidemiological studies have evaluated the usefulness of $\gamma \mathrm{GT}$ serum levels as a marker of morbidity and mortality (Paolicchi et al. 1996; Kazemi-Shirazi et al. 2007; Huang et al. 2014). Kazemi-Shirazi et al. (2007) reported a strong association between increased $\gamma$ GT levels and death from liver diseases, including cancer and vascular disorders. The analysis of the correlation between $\gamma$ GT levels and prognosis after hepatocellular carcinoma (HCC) treatment with transcatheter arterial chemoembolization (TACE) indicated that increased $\gamma$ GT serum levels seems to be an effective predictor of poor prognosis (Guiu et al. 2012; Zhang et al. 2011). Our objective was to evaluate the ductular reaction, the positivity of cytokeratin 7 , and $\gamma$ GT levels in precancerous lesions and advanced HCC in rats with liver carcinogenesis. We investigated the existence of a correlation between cytokeratin 7 positivity (PCK7) and levels of $\gamma \mathrm{GT}$ in diethylnitrosamine (DEN)-induced HCC and correlated PCK7 with the liver DNA damage index and the expression of oxidative stress proteins.

\section{Materials and methods}

\section{Animals and protocol}

Male Wistar rats $(n=30)$ weighing $145-150 \mathrm{~g}$ were obtained from the Central Animal Laboratory at the Federal University of Pelotas, Brazil. Rats were caged at $24{ }^{\circ} \mathrm{C}$ in a 12 -h lightdark cycle with free access to food and water until the time of experiments in the Hospital de Clínicas de Porto Alegre Experimental Animal Division. All experiments were performed in accordance with the Guiding Principles for Research Involving Animals (NAS) and were approved by the Ethics in Research Committee (protocol 120355).

HCC was induced by chronic intermittent exposure to 50 or $100 \mathrm{mg} / \mathrm{kg}$ DEN (Sigma-Aldrich, St. Louis, MO, USA). The animals were divided into three groups: (I) control (CO) -6 animals received only vehicle (saline); (II) precancerous lesions (PL) - 12 animals received DEN at dose of $100 \mathrm{mg} / \mathrm{kg}$ body weight i.p. once a week every 6 weeks up to 28 weeks; and (III) advanced HCC -12 animals received DEN at a dose of $50 \mathrm{mg} / \mathrm{kg}$ body weight i.p. twice a week for the first 3 weeks and once per week from weeks 4 to 6 and 11 to 13 weeks. A single dose of 2acetylaminofluorene (2-AAF, $100 \mathrm{mg} / \mathrm{kg}$, Sigma-Aldrich, St. Louis, MO) was administered in week 4 to both DEN groups (Moreira et al. 2015).

After fasting for $12 \mathrm{~h}$, the animals were anesthetized with ketamine hydrochloride (Ketalar ${ }^{\circledR} 100 \mathrm{mg} / \mathrm{kg}$ ) and xylazine $(50 \mathrm{mg} / \mathrm{kg})$, and blood was collected for biochemical analyses. The induction of HCC was confirmed by visual inspection, and liver samples were collected from lobes with nodules for histological, biochemical, and molecular analyses. Animals were killed at the end of the experiment by exsanguination under deep anesthesia, as described in the American Veterinary Medical Association (AVMA) Guidelines on Euthanasia (AVMA 2013).

\section{Biochemical analysis}

The enzymes were measured at the Hospital de Clínicas de Porto Alegre using enzymatic methods (automatedSiemens Advia 1800 Chemistry system). Alanine aminotransferase (ALT) (U/L) and aspartate aminotransferase (AST) $(\mathrm{U} / \mathrm{L})$ were measured by the kinetic ultra violet test. $\gamma \mathrm{GT}(\mathrm{U} / \mathrm{L})$ and alkaline phosphatase (AP) (U/L) were quantified by kinetic colorimetric assay. 


\section{Histology and immunohistochemical analysis, sample preparation, and image capture}

For histology, a specimen of liver was trimmed and fixed by immersion in $10 \%$ buffered formalin for $24 \mathrm{~h}$. The blocks were dehydrated in a graded ethanol series and embedded in paraffin wax. Serial 3- $\mu$ m sections were stained with hematoxylin and eosin. For immunohistochemical analysis, slides of the liver were stained and incubated with anti-cytokeratin 7 (CK7) (1:50 dilution, Ab9021 Abcam) for $1 \mathrm{~h}$ at room temperature. For morphometric measurements, 10 images from each slide were captured from randomly selected highpower fields $(\times 200$ magnification) containing CK7-positive structures. Morphometric assessment of the percentage of CK7-positive areas (PCK7) was performed using Adobe Photoshop CS5 Extended 10.0 (Adobe Systems, San Jose, CA) as previously described (Souza et al. 2014). The analyses were performed by a blinded evaluator.

\section{Comet assay}

The alkaline comet assay was performed as described by Tice et al. with minor modifications (Tice et al. 2000; Hartmann et al. 2003). Images of 100 randomly selected cells (50 cells from each of two replicate slides) were analyzed for each animal. Cells were also visually scored according to tail size into five classes of damage index (DI), ranging from undamaged $(0,100$ cells $\times 0$ ) to maximally damaged $(400,100$ cells $\times 4)$. This produced a single DNA damage score for each animal and consequently for each group. Damage frequency (DF) was calculated based on the number of cells with tail versus those with no tail. The analyses were performed by a blinded evaluator.

\section{Western blot}

Western blot analysis was performed on nuclear and cytosolic extracts prepared by liver tissue homogenization in $140 \mathrm{mM}$ $\mathrm{NaCl}, 15 \mathrm{mM}$ EDTA, $20 \mathrm{mM}$ glycerol (10\%), and a protease inhibitor cocktail (Laemmli 1970). Protein concentrations were measured by the Bradford assay (Bradford 1976). Samples containing 50-100 $\mu \mathrm{g}$ of protein were separated by sodium dodecyl sulfate-polyacrylamide gel electrophoresis (9-12\% acrylamide) and transferred to polyvinylidene fluoride membranes. The membranes were probed overnight at $4{ }^{\circ} \mathrm{C}$ with polyclonal antibodies against inducible nitric oxide synthase (iNOS - SC7271/130 kDa), nicotinamide adenine dinucleotide phosphate quinone oxidoreductase 1 (NQO1-SC376023/31 kDa), and nuclear factor erythroid 2-related factor 2 (nuclear extract-Nrf2-SC 30915/ $57 \mathrm{kDa}$ ) (Santa Cruz Biotechnology, Santa Cruz, CA, USA) at a 1:200-1:1000 dilution. Antibodies against heat shock factor protein 1 (nuclear extract HSF-1-H4163/75 kDa) and heat shock protein 70 (HSP70-H5147/ 73 and $72 \mathrm{kDa})$
(Sigma-Aldrich, St Louis, MO, USA) were used at a 1:5000 dilution. An against glyceraldehyde 3-phosphate dehydrogenase (GAPDH - G9545/37 kDa) antibody (Sigma-Aldrich) was used at 1:500-1:1000 dilution. After washing with TTBS, the membranes were incubated for $1 \mathrm{~h}$ at room temperature with a secondary HRP-conjugated antibody (Santa Cruz Biotechnology). Protein detection was performed via chemiluminescence using a commercial ECL kit (Amersham Pharmacia Biotech, Little Chalfont, Great Britain) (Tuñón et al. 2013). The density of the specific bands was quantified with L-Pix Chemi software.

\section{Statistical analysis}

Means and standard deviations (SD) were calculated for all data. Significant differences between means were evaluated by one-way analysis of variance (ANOVA). In the presence of significance, Tukey's test was also applied ( $p$ values $<0.05$ were deemed significant). Pearson's chi-square and Spearman's tests were used for correlation analyses. Qualitative variables were examined with cross-table analysis with significance at $p<0.05$. All analyses were performed in SPSS 18.0.

\section{Results}

After DEN administration, rats developed precancerous lesions (PL) and advanced HCC (Table 1). The groups were correlated with the $\gamma \mathrm{GT}$ levels (ranges $\leq 5 \mathrm{U} / \mathrm{L}$, between 6 and $39 \mathrm{U} / \mathrm{L}$, and $\geq 40 \mathrm{U} / \mathrm{L}$ ). We observed that group III exhibited high levels of $\gamma \mathrm{GT}$.

\section{Biochemical analysis}

Levels of transaminases (AST and ALT) were increased in group III. AP and $\gamma$ GT were significantly increased in group III relative to groups I and II (Table 2).

\section{Pathological finding}

Microscopy observations revealed that group I showed normal hepatic parenchyma. Group II exhibited nodules of regeneration, precancerous lesions with fibrosis, and cirrhotic pattern. Group III was characterized by HCC, chronic damage, and areas of cellular atypia. Loss of normal hepatic parenchyma was present, with a pseudo-acinar and trabecular growth pattern (Fig. 1a). Immunohistochemical preparations performed in normal liver sections from animals of group I revealed expected CK7 localization in bile ducts of portal tracts (Fig. 1bI-arrow). Group II showed moderate positivity of CK7 in dysplastic areas, concomitant with increased number of ducts around regenerating nodules (Fig. 1bII—black arrows). Group III exhibited increased numbers of cancerous bile ducts 
Table 1 Correlation between the groups CO, PL advanced HCC, and gamma-glutamyl transferase levels

\begin{tabular}{|c|c|c|c|c|c|c|}
\hline Cross-table & \multicolumn{2}{|c|}{$\gamma \mathrm{GT}$ levels $(\mathrm{U} / \mathrm{L})$} & $<5 \mathrm{U} / \mathrm{L}$ & $6-39 \mathrm{U} / \mathrm{L}$ & $>40 \mathrm{U} / \mathrm{L}$ & \\
\hline \multicolumn{3}{|c|}{ Groups } & & (n) & & Iotal \\
\hline \multicolumn{3}{|c|}{$\mathrm{CO}$} & 6 & & & 6 \\
\hline \multicolumn{3}{|c|}{ PL } & 3 & 6 & 1 & 10 \\
\hline \multicolumn{3}{|c|}{ Advanced HCC } & & & 11 & 11 \\
\hline \multirow[t]{2}{*}{ Total } & & & 9 & 6 & 12 & 27 \\
\hline & & & \multicolumn{2}{|c|}{ Value } & $\mathrm{df}$ & Significance \\
\hline \multicolumn{3}{|c|}{ Pearson's chi-square } & \multicolumn{2}{|c|}{$34.875^{\mathrm{a}}$} & 4 & .000 \\
\hline \multirow{2}{*}{\multicolumn{3}{|c|}{$\begin{array}{l}\text { Linear by linear association } \\
\qquad \mathrm{n}\end{array}$}} & \multicolumn{2}{|c|}{39.327} & 4 & .000 \\
\hline & & & \multicolumn{2}{|c|}{27} & & 27 \\
\hline & & value & \multicolumn{2}{|c|}{ Sig of standard error } & Aprox $\chi$ & Aprox Sig \\
\hline \multicolumn{2}{|l|}{ Pearson of $\mathrm{R}$} & 0.902 & \multicolumn{2}{|c|}{.044} & 10.4 & .000 \\
\hline \multicolumn{2}{|c|}{ Spearman's correlation } & 0.912 & \multicolumn{2}{|c|}{.045} & 11.1 & .000 \\
\hline $\mathrm{n}$ & & 27 & & & & \\
\hline
\end{tabular}

and neoplastic cholangiocytes exhibiting robust immunoreactivity for CK7- PCK7 (\%): group I (a) $=1.32 \pm 0.7$; group II $^{(\mathrm{b})}=3.38 \pm 0.4$; group III $=6.07 \pm 2.2-^{\mathrm{a}} p<0.001$ group I vs. groups II and III. ${ }^{\mathrm{b}} p<0.001$ group II vs. group III. Tukey's test). PCK7 was higher in animals with high $\gamma$ GT levels (Fig. 3-the correlation between cytokeratin 7

Table 2 Stage effects of DEN-induced carcinogenesis on weight, hepatosomatic index, serum levels of aspartate aminotransferase, alanine aminotransferase, alkaline phosphatase, $\gamma$ glutamyl transferase, and comet assay (damage index and damage frequency)

\begin{tabular}{llll}
\hline & \multicolumn{2}{l}{ Groups } & \\
\cline { 2 - 4 } & I CO & II PL & III Advanced HCC \\
\hline Initial weight (g) & $157.8 \pm 12$ & $164 \pm 11$ & $149.1 \pm 11$ \\
Final weight (g) & $487.1 \pm 26$ & $340.7 \pm 42^{\mathrm{b}}$ & $315.5 \pm 43^{\mathrm{a}}$ \\
HSI (\%) & $3.0 \pm 0.17$ & $4.3 \pm 0.9$ & $9.3 \pm 5.4^{\mathrm{a}}$ \\
AST (U/L) & $130.7 \pm 16$ & $143 \pm 23^{\mathrm{b}}$ & $230.8 \pm 68^{\mathrm{a}}$ \\
ALT (U/L) & $60.2 \pm 8$ & $89 \pm 10^{\mathrm{b}}$ & $144.3 \pm 33^{\mathrm{a}}$ \\
AP (U/L) & $117 \pm 30$ & $193.1 \pm 62$ & $285.6 \pm 76^{\mathrm{a}}$ \\
$\gamma \mathrm{GT}(\mathrm{U} / \mathrm{L})$ & $1 \pm 1.3$ & $23.7 \pm 12^{\mathrm{b}}$ & $85.5 \pm 28^{\mathrm{a}}$ \\
DI & $95.8 \pm 27$ & $191.3 \pm 78^{\mathrm{b}}$ & $291.1 \pm 89^{\mathrm{a}}$ \\
DF & $74.7 \pm 17$ & $78 \pm 18$ & $91 \pm 12$ \\
\hline
\end{tabular}

Values are means \pm standard deviation (SD) for 7-10 rats

$H S I$ hepatosomatic index, $A S T$ aspartate aminotransferase, $A L T$ alanine aminotransferase, $A P$ alkaline phosphatase, $\gamma G T$ gamma-glutamyl transferase, $D I$ damage index (completely undamaged 0 ; maximum damage $400), D F$ damage frequency, calculated based on the number of cells with tail versus those with no tail. Tuckey's test

${ }^{\mathrm{a}} p<0.05$ vs. groups I and II

${ }^{\mathrm{b}} p<0.05$ vs. group I positivity with $\gamma \mathrm{GT}$ levels was significant at the $p<0.01$, $r^{2}=0.53$-Pearson's correlation). Overall, full-blown and advanced HCC lesions displayed a significantly more widespread and robust CK7 immunoreactivity (Fig. 1bIII) as compared to early lesions of HCC or preneoplastic lesions, which mirrors the overt proliferation of duct-forming neoplastic epithelial cells in the former group (Fig. 1aIII, bIII).

\section{Comet assay}

DI and DF were significantly higher in group III than in group I (Table 2). $\gamma \mathrm{GT}$ levels and PCK7 were positively correlated with DI and DF $(p<0.01)$ (Table $3 \mathrm{~B}, \mathrm{C})$.

\section{Nrf2, NQO1, iNOS, HSF-1, and HSP 70 (73 and 72 kDa) expression}

Proteins of oxidative stress were evaluated. Underexpression of Nrf2 was observed in group III, with high $\gamma \mathrm{GT}$ levels and PCK7, whereas overexpression of Nrf2 was observed in group II. Induction of NQO1 was more marked in group III than in group I. iNOS and HSF-1 expression were increased in animals with high PCK7. However, iHSP expression was depleted in these animals (Fig. 2).

\section{Correlation between:}

CK7 positivity (PCK7) and $\gamma G T$ levels: in our study, we found a strong correlation between CK7 positivity and $\gamma \mathrm{GT}$ levels, with statistical significance $(p<0.01$, $r^{2}=0.53$ ) (Fig. 3). 


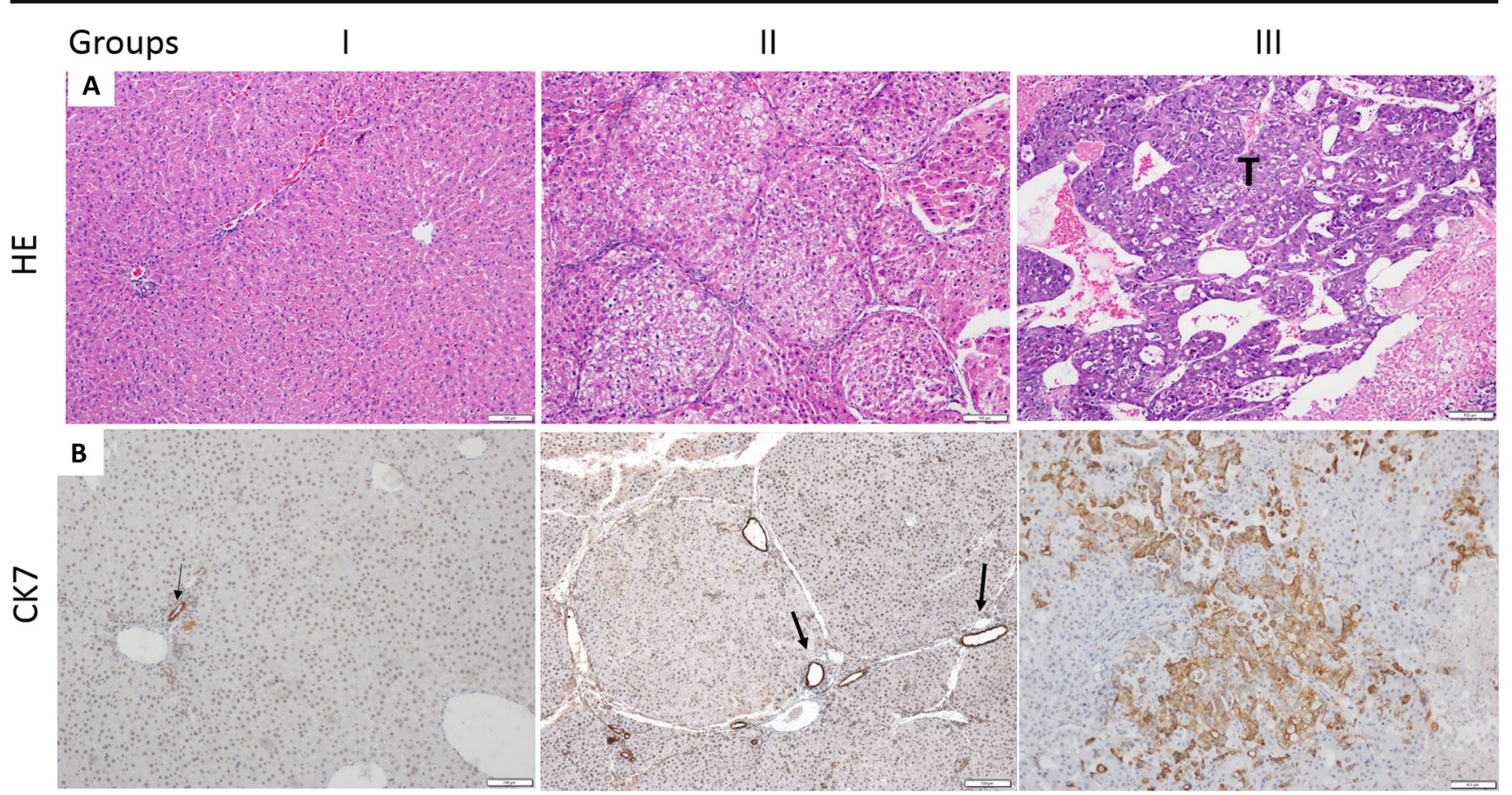

Fig. 1 a Photomicrographs of liver sections stained with hematoxylineosin $(H E)$ : Group I: normal hepatic parenchyma. Group II: exhibited multiple nodules of regeneration, fibrosis, and cirrhotic pattern. Group III: The liver histology was characterized by chronic damage and areas of cellular atypia ( $T$ tumor). Loss of normal hepatic parenchyma $(H P)$ was present, with a pseudo-acinar and trabecular growth pattern (original magnification $\times 10$. Hematoxylin-eosin). b
Positivity for cytokeratin 7: Group I showed normal hepatic parenchyma and low positivity of cytokeratin 7 protein. Black arrow CK 7 was positive in bile ducts in portal tract. b Group II: Preneoplastic lesions exhibited CK7 positivity around the cirrhotic nodules (black arrow). c Group III: Advanced HCC shows extensive and robust $\mathrm{CK} 7$ labeling in duct-forming neoplastic epithelial cells (original magnification $\times 200$. CK7 cytokeratin 7)
Table 3 Correlation between A) gamma-glutamyl transferase levels and protein expression, B) gamma-glutamyl transferase levels and damage of liver deoxyribonucleic acid of animals exposed to diethylnitrosamine, and C) cytokeratin 7 positive and damage of liver deoxyribonucleic acid of animals exposed to diethylnitrosamine

\begin{tabular}{clll}
\hline Correlated variable & \multicolumn{2}{l}{ Statistical analysis_Pearson correlation } \\
\hline A) Protein expression & $R$ & $R$ square & Significance \\
$\gamma$ GT vs. iNOS & 0.924 & 0.854 & $0.001^{\mathrm{a}}$ \\
$\gamma$ GT vs. HSF-1 & 0.852 & 0.726 & $0.023^{\mathrm{a}}$ \\
$\gamma$ GT vs. iHSP70 & -0.926 & 0.858 & $0.002^{\mathrm{a}}$ \\
$\gamma$ GT vs. Nrf2 & -0.792 & 0.627 & $0.039^{\mathrm{a}}$ \\
B) Comet assay & $R$ & $R$ square & Significance \\
$\gamma$ GT vs. DI & 0.607 & 0.369 & $0.01^{\mathrm{a}}$ \\
$\gamma$ GT vs. DF & 0.393 & 0.155 & 0.053 \\
C) Comet assay & $R$ & $R$ square & Significance \\
PCK7 vs. DI & 0.722 & 0.521 & $0.001^{\mathrm{a}}$ \\
PCK7 vs. DF & 0.556 & 0.309 & $0.01^{\mathrm{a}}$ \\
\hline
\end{tabular}

$\gamma G T$ gamma-glutamyl transferase, iNOS inducible nitric oxide synthase, $H S F-1$ heat shock factor protein $1, i H S P 70$ inducible heat shock protein 70, Nrf2 nuclear factor erythroid 2-related factor 2, PCK7 cytokeratin 7 positive, $D I$ damage index, $D F$ damage frequency

${ }^{\text {a }}$ Correlation is significant at the 0.05 level (Pearson's chi-square) $\gamma$ GT levels and iNOS, HSF-1, HSP70, and Nrf2 expression: our results showed strong positive correlations between $\gamma \mathrm{GT}$ levels with iNOS and HSF-1 expression $(p<0.01)$. On the other side, an inverse correlation between $\gamma$ GT levels with iHSP and Nrf2 expressions was recorded (Table $3 \mathrm{~A})$.

CK7 positivity (PCK7) and iNOS, HSF-1, HSP70, and Nrf2 expression: we observed strong positive correlations between PCK7 with iNOS and HSF-1 expression $(p<0.01)$. Furthermore, an inverse correlation between PCK7 with iHSP and Nrf2 expressions was recorded (Fig 3).

\section{Discussion}

The present study investigated the presence of ductular reaction in multiple steps of DEN-induced hepatocarcinogenesis. We examined the correlation between CK7 positivity and the levels of $\gamma \mathrm{GT}$ in multistage of liver cancer in rats. Furthermore, we evaluated the relationship between PCK7 and tumor incidence, damage index of liver DNA, and the expression of oxidative stress proteins. Our results indicate 
A

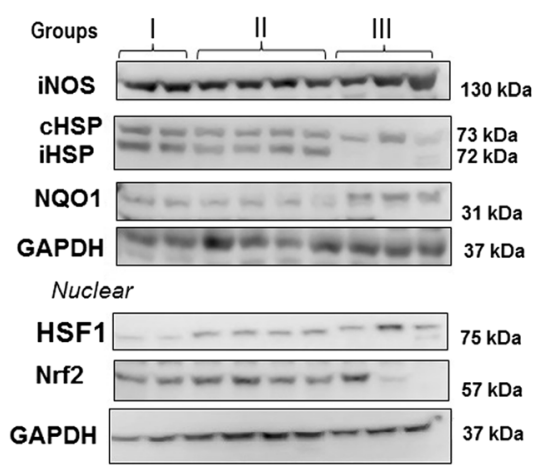

B

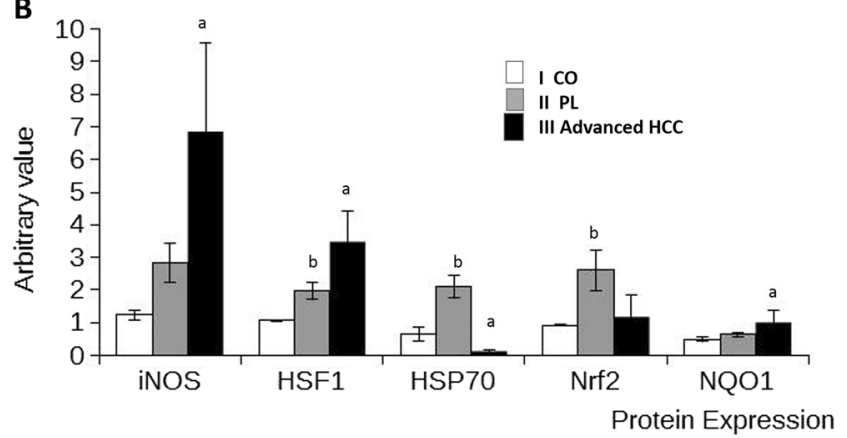

Fig. 2 Western blot analysis of inducible nitric oxide synthase, heat shock factor protein 1 , heat shock protein $70(72 \mathrm{kDa})$, nuclear factor erythroid 2-related factor 2, and nicotinamide adenine dinucleotide phosphate quinone oxidoreductase 1. Protein from liver extracts was separated by sodium dodecylsulfate-polyacrylamide gel electrophoresis followed by immunoblotting. a Representative images. b Densitometric quantification. Arbitrary values are expressed as the means \pm standard deviation $(n=5)^{\mathbf{a}} p<0.05$ group III vs. groups I and II. ${ }^{\mathbf{b}} p<0.05$ group II vs. groups I and III. Tukey's test. iNOS inducible nitric oxide synthase, $H S F-1$ heat shock factor protein $1, c H S P 70$ constitutive heat shock protein $70, i H S P 70$ inducible heat shock protein $70, N r f 2$ nuclear factor erythroid 2-related factor 2, NQO1 nicotinamide adenine dinucleotide phosphate quinone oxidoreductase 1, GAPDH glyceraldehyde 3phosphate dehydrogenase

that the extent of PCK 7 correlated with high levels of $\gamma \mathrm{GT}$ and with the aggressiveness of HCC.

Our model developed advanced HCC in 19 weeks with histological and biochemical characteristics very similar to human HCC. The histological patterns found in group III were pseudo-acinar and trabecular. The AST, ALT, AP, and $\gamma \mathrm{GT}$ had an increase compatible with hepatocellular injury and cholestatic disease.

Biochemical results were different for group III compared with the other two groups, indicating liver damage resulting from necrosis or changes in cell membrane permeability. Increased serum levels of $\gamma \mathrm{GT}$ and AP indicate cholestasis and cholangitis, potentially associated with mechanical biliary obstruction. In this study, the nodule size observed on histological analysis suggests that tumor nodules compressed bile ducts, thus producing mechanical obstruction to bile flow (Moreira et al. 2015).
Animals with high $\gamma \mathrm{GT}$ levels exhibited advanced HCC, whereas animals with $\gamma \mathrm{GT}$ levels between 6 and $39 \mathrm{U} / \mathrm{L}$ developed precancerous lesions or early HCC. DEN and 2-AAF are powerful hepatocarcinogenic agents (Williams et al. 1996). DEN is hydrolyzed in nitrosamine, generating an electrophilic radical, whereas 2-AAF forms adducts with DNA following N-hydroxylation by cytochrome CYP1A2 in the liver and inhibits the proliferation of normal hepatocytes (Malik et al. 2013; Bagnyukova et al. 2008; Poirier 2002). Group III developed HCC, exhibiting large nodules. The small nodules in group II were consistent with precancerous lesions. Dysplastic nodules (DN) are precancerous lesions in hepatocarcinogenesis according to Wong and $\mathrm{Ng}$ (2008) and the criteria of Thoolen et al. (2012).

Our animals with advanced HCC exhibited extremely high values of $\gamma \mathrm{GT}$ and PCK7, whereas the animals with precancerous lesions exhibited lower $\gamma$ GT levels and PCK7. The histological results were normal in all animals with $\gamma \mathrm{GT}$ below $5 \mathrm{U} / \mathrm{L}$ and without PCK7. Increased $\gamma$ GT levels have been associated with ductular reaction and thus with biliary lesions. Ductular reaction is a risk factor for cancer (Guiu et al. 2012; Desmet 2011). During carcinogenesis, $\gamma$ GT seems to be involved in the activation of pro-oncogenes or in the inactivation of tumor suppressor genes (Hanigan et al. 1999).

Numerous studies have demonstrated the involvement of ductular reaction (DR) in the pathogenesis of progressive fibrosis, regeneration in chronic liver disease, and hepatocarcinogenesis (Ye et al. 2014; Roskams et al. 2004). DR involves increased numbers of bile ducts with a complex infiltration of stromal and inflammatory cells. According to $\mathrm{Ye}$ et al. (2014), the DR status reflects indefinite proliferation in HCC (Ye et al. 2014). We observed higher CK7 positivity in livers with advanced HCC and high $\gamma$ GT levels. An increased area of CK7 positivity could be attributable to cholangitis or mechanical obstruction of mature bile ducts, generating a "typical" ductular reaction. Conversely, a change in cytoskeletal filament organization during neoplastic transformation could induce a shift of the cytokeratin pattern from hepatocystic to biliary in liver cells, producing an "atypical" ductular reaction (Denk 1984). The ability of tumor cells of hepatocellular origin to express a biliary cytokeratin profile may contribute to the very high levels of $\gamma \mathrm{GT}$ in HCC (Van Eyken et al. 1988; Gould 1986). The ductular reaction evidenced by the increased area of CK 7 positivity could justify the increased levels of $\gamma \mathrm{GT}$ in group III. In the control group, no changes in PCK7 or $\gamma$ GT levels were observed. These data suggest that the presence of ductular reaction, including changes in the cytoskeletal structure, may be associated with liver cancer aggravation. Zhang et al. (2013) reported that early HCC had less ductular reaction than advanced $\mathrm{HCC}$ (nodules more than $3 \mathrm{~cm}$ ).

DNA damage was assessed by comet assay, which evaluated DEN-induced DNA strand breaks in liver tissue. DEN 

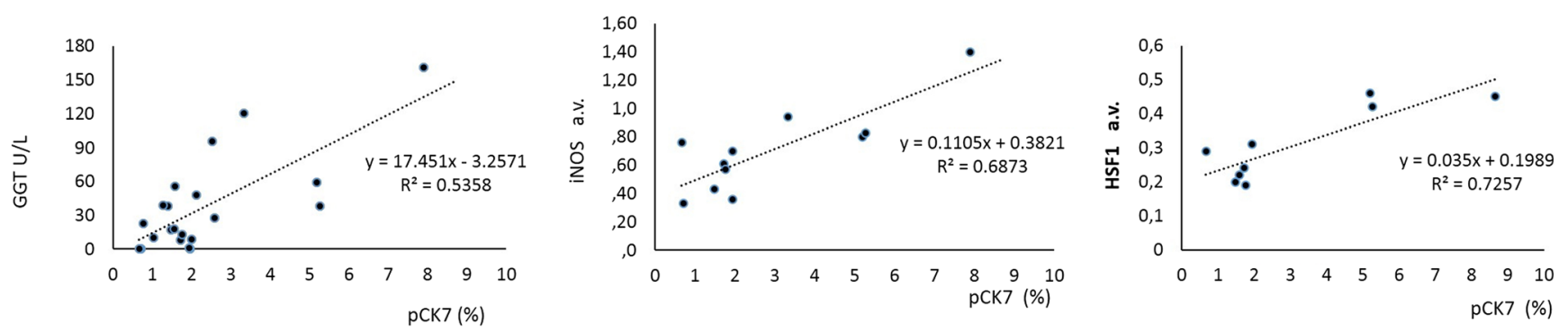

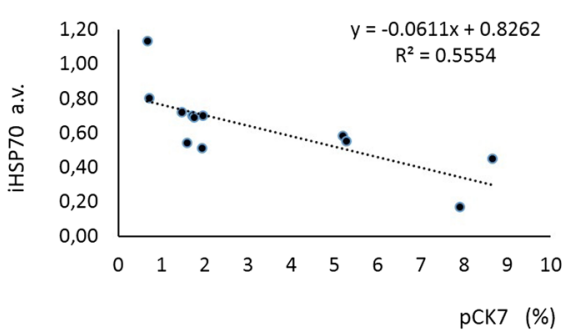

Fig. 3 Correlation between cytokeratin 7 positivity with gamma-glutamyl transferase levels and protein expression (iNOS, HSF-1, iHSP70, and $\mathrm{NrF} 2)$. All correlations were statistically significant $(p<0.01)$ Pearson's correlation. PCK7 cytokeratin 7 positivity, $\gamma G T$ gamma-glutamyl

treatment induced a higher damage index (DI) in liver DNA. DEN produces promutagenic DNA lesions, inducing hepatocarcinogenesis. These lesions are caused by alkylation and DNA adducts that are triggered by DEN + 2-AAF (Santos et al. 2014; Kang et al. 2007; El Mesallamy et al. 2011; Verna et al. 1996). Alkylating agents, free radicals, and reactive oxygen species (ROS) generated by environmental carcinogens or metabolic alterations thus cause DNA damage and genetic instability (Srinivasan et al. 2008). Our study revealed a strong correlation between a high index of DNA damage and increased PCK7 and levels of $\gamma$ GT. According to Van Eyken et al. (1988), the presence of high cytokeratin expression in HCC appears to be associated with an increase in the atypia of hepatocytes, which start to secrete $\gamma$ GT (Van Eyken et al. 1988).

Redox regulation of genes responsive to ROS/electrophiles seems to modulate $\gamma \mathrm{GT}$ expression; this could explain the high $\gamma$ GT levels observed in HCC (Zhang et al. 2006; Pandur et al. 2007). In this study, Nrf2 expression was correlated with PCK7 and $\gamma$ GT levels. In cancer, Nrf2 behaves in a complex way, acting either as an oncogenic molecule or as a tumor suppressor (Sporn and Liby 2012; Kensler and Wakabavashi 2010). We observed that animals with extensive PCK7 and high $\gamma$ GT levels exhibited underexpression of Nrf2. Conversely, Nrf2 was overexpressed in animals with low $\gamma$ GT levels. $\gamma$ GT plays a dual role in the oxidative/ antioxidative system - it increases resistance to pro-oxidant drugs and replenishes GSH. As such, $\gamma$ GT appears to act as a component of the cellular defensive systems (Pompella et al. 2006; Corti et al. 2010). Another line of evidence suggests that $\gamma \mathrm{GT}$ can exert pro-oxidant effects, modulating redox-sensitive processes (Corti et al. 2010).
We studied the behavior of NO, evaluating iNOS expression in the cytoplasmic extracts of liver and correlating iNOS expression with extent PCK7 and $\gamma$ GT levels. Additionally, iNOS overexpression has been associated with numerous inflammatory stimuli. Wei et al. (2002) reported that during the process of cirrhosis, high levels of arginase II are released by destroyed hepatocytes, leading to the conversion of plasma arginine to ornithine. This process may regulate NO production in liver diseases. Arginine is an amino acid in animal cells that serves as a precursor for the synthesis of NO, urea, polyamine, proline, and glutamate (Wei et al. 2002). Arginase is an enzyme that catalyzes rate-controlling steps in arginine synthesis and catabolism and represents a new marker for HCC (Sang et al. 2015). We observed that group with HCC exhibited intense DR, extensive PCK7, and high $\gamma$ GT levels, as well as strong expression of iNOS protein. HCC development exhibit high expression of iNOS and increased nitrosative stress (Tang et al., 2013; Iwakiri and Kim, 2015).

Other characteristics evaluated in the present study included HSF-1 expression, which was significantly correlated with PCK 7 and $\gamma$ GT levels. Chuma et al. (2014) reported that HSF-1 accelerates the development of HCC and that HSF-1 deficiency significantly diminished nuclear factor kappa B and mitogen-activated protein kinase activation in HCC hepatocytes. The overexpression of HSF-1 can be regulated by inhibition of HSP70 (Chuma et al. 2014). We believe that a strong reduction of HSP70 could be the trigger to stimulate HSF-1. Vydra et al. (2014) explained that the pleiotropic effects of HSF-1 may explain its influence on many aspects of cellular metabolism that promote tumor growth. The combination of three proteins, glypican-3 (GPC-3), glutamine 
synthetase (GS), and heat shock protein 70 (HSP70) prove to be very good for the diagnosis of HCC (Jain 2014). Previous studies comparing gene expression in $\mathrm{HCC}$ vs. other hepatocellular nodules have indicated that the HSP70 gene is able to differentiate high-grade dysplastic nodules from early HCC (Shafizadeh and Kakar 2011). High expression of HSP70 has been associated with early stage HCC (Chuma et al. 2014; Boonjaraspinyo et al. 2012; Khalil et al. 2011; Chuma et al. 2003). Heat shock proteins (HSPs) are highly conserved proteins that play a role in the regulation of cell cycle progression and apoptosis (Shafizadeh and Kakar 2011). Our study demonstrated first an increase in HSP70 expression in group II and a negative correlation between PCK7 and $\gamma$ GT levels with iHSP expression.

Our data support the clinical observations recorded in numerous clinical studies that describe the close relationship between the worsening of hepatocellular carcinoma with increased $\gamma$ GT levels. Our study presents strong relationships between $\gamma \mathrm{GT}$ and important proteins involved in liver carcinogenesis. In recent years, several studies have suggested that patients with HCC treated with TACE or surgical treatment had better prognosis, clinical outcome, and overall survival when $\gamma \mathrm{GT}$ levels were reduced. Conversely, increased $\gamma \mathrm{GT}$ levels indicate the worsening of the disease and failure of the treatment (Fu et al. 2015; Song et al. 2015; Yang et al. 2015).

In conclusion, we observed a progressive increase in PCK7 and $\gamma \mathrm{GT}$ levels associated with worsening of HCC. Furthermore, CK7 positivity and elevated $\gamma$ GT levels were associated with more extensive ductular reaction and overexpression of protein iNOS and HSF-1. Conversely, CK7 positivity and $\gamma \mathrm{GT}$ levels were negatively correlated with nuclear factor erythroid 2-related factor 2 (NRF2) and iHSP protein expression. These results suggest that ductular reaction is involved in the multistage formation of HCC. Although DR cannot be considered a tumor marker for diagnosis, it may be useful as a marker for worsening prognosis.

Acknowledgments We wish to thank Dr. Widlak and our group for the important contribution to the understanding of the role of HSF-1. This study was supported by grants from the following Brazilian agencies: Conselho Nacional de Desenvolvimento Científico e Tecnológico (CNPq), Coordenação de Aperfeiçoamento de Pessoal de Nível Superior (CAPES), Fundo de Incentivo à Pesquisa e Eventos (FIPE) of the Hospital de Clínicas of Porto Alegre (HCPA), Fundação de Amparo à Pesquisa do Estado do Rio Grande do Sul (FAPERGS), and Laboratório Experimental de Hepatologia e Gastroenterologia (HCPA/UFRGS).

Compliance with ethical standards All experiments were performed in accordance with the Guiding Principles for Research Involving Animals (NAS) and were approved by the Ethics in Research Committee (protocol 120355 - Ethical Committee of Hospital de Clínicas de Porto Alegre). Animals were killed at the end of the experiment by exsanguination under deep anesthesia, as described in the American Veterinary Medical Association (AVMA) Guidelines on Euthanasia (AVMA 2013).
Conflict of interest The authors declare that they have no conflict of interest.

\section{References}

AVMA Guidelines for the Euthanasia of animals: 2013 edition pp 1-102. Bagnyukova TV, Tryndyak VP, Montgomery B, Churchwell MI, Karpf AR, James SR, Muskhelishvili L et al (2008) Genetic and epigenetic changes in rat preneoplastic liver tissue induced by 2acetylaminofluorene. Carcinogenesis 29:638-646

Boonjaraspinyo S, Boonmars T, Kaewkes S, Laummaunwai P, Pinlaor S, Loilome W, Yongvanit P et al (2012) Down-regulated expression of HSP70 in correlation with clinicopathology of cholangiocarcinoma. Pathol Oncol Res 18:227-237

Bradford MM (1976) A rapid and sensitive method for the quantitation of microgram quantities of protein utilizing the principle of protein-dye binding. Anal Biochem 72:248-254

Bruix J, Boix L, Sala M, Llovet JM (2004) Focus on hepatocellular carcinoma. Cancer Cell 5:215-219

Chuma M, Sakamoto M, Yamazaki K, Ohta T, Ohki M, Asaka M, Hirohashi S, Asaka M, Hirohashi S (2003) Expression profiling in multistage hepatocarcinogenesis: identification of HSP70 as a molecular marker of early hepatocellular carcinoma. Hepatology 37:198-207

Chuma M, Sakamoto N, Nakai N, Hige S, Nakanishi M, Natsuizaka M, Suda G et al (2014) Heat shock factor 1 accelerates hepatocellular carcinoma development by activating nuclear factor-kB/mitogenactivated protein kinase. Carcinogenesis 35:272-281

Corti A, Franzini M, Paolicchi A, Pompella A (2010) Gamma-glutamyl transferase of cancer cells at the crossroads of tumor progression, drug resistance and drug targeting. Anticancer Res 30:1169-1182

Denk H (1984) The intermediate filament cytoskeleton in neoplastic and non-neoplastic liver disorders. J Submicrosc Cytol 16:141-145

Desmet V (2011) Ductal plates in hepatic ductular reactions. Virchows Arch 458:251-259

Durnez A, Verslype C, Nevens F, Fevery J, Aerts R, Pirenne J, Lesaffre E, Libbrecht L, Desmet V, Roskams T (2006) The clinicopathological and prognostic relevance of cytokeratin 7 and 19 expression in hepatocellular carcinoma. A possible progenitor cell origin. Histopathology 49:138-151

El Mesallamy H, Metwally N, Soliman MS, Ahmed K, Moaty MM (2011) The chemopreventive effect of Ginkgo biloba and Silybum marianum extracts on hepatocarcinogenesis in rats. Cancer Cell Int $11: 38$

Ferlay J, Shin HR, Bray F, Forman D, Mathers C, Parkin DM (2010) Estimates of worldwide burden of cancer in 2008: GLOBOCAN 2008. Int J Cancer 127:2893-2917

Fu S, Guo Z, Li S, Kuang M, Hu W, Hua Y, He X, Peng B (2015) Prognostic value of preoperative serum gamma-glutamyltranspeptidase in patients with hepatocellular carcinoma after hepatectomy. Tumor Biol. doi:10.1007/s13277-015-4136-1

Gould VE (1986) Histogenesis and differentiation: a re-evaluation of these concepts as criteria for the classification of tumors. Hum Pathol 17:212-215

Guiu B, Deschamps F, Boulin M, Boige V, Malka D, Ducreux M, Hillon P, de Baère T (2012) Serum gamma glutamyl transferase independently predicts outcome after transarterial chemoembolization of hepatocellular carcinoma: external validation. Cardiovasc Intervent Radiol 35: $1102-1108$

Hanigan MH, Gallagher BC, Townsend DM, Gabarra V (1999) Gammaglutamyl transpeptidase accelerates tumor growth and increases the resistance of tumors to cisplatin in vivo. Carcinogenesis 20:553-559 
Hartmann A, Agurell E, Beevers C, Brendler-Schwaab S, Burlinson B, Clay P, Collins A et al (2003) Recommendations for conducting the in vivo alkaline Comet assay. 4th International Comet Assay Workshop. Mutagenesis 18:45-51

Huang CF, Yeh ML, Tsai PC, Hsieh MH, Yang HL, Hsieh MY, Yang JF et al (2014) Baseline $\gamma$ GT levels strongly correlate with hepatocellular carcinoma development in non-cirrhotic patients with successful hepatitis C virus eradication. J Hepatol 61(1):67-74

Iwakiri Y, Kim MY (2015) Nitric oxide in liver diseases. Trends Pharmacol Sci 36(n8):524-536

Jain D (2014) Tissue diagnosis of hepatocellular carcinoma. J Clin Exp Hepatol 4:S67-S73

Kang JS, Wanibuchi H, Morimura K, Gonzalez FJ, Fukushima S (2007) Role of CYP2E1 in diethylnitrosamine induced hepatocarcinogenesis in vivo. Cancer Res 67:11141-11146

Kazemi-Shirazi L, Endler G, Winkler S, Schickbauer T, Wagner O, Marsik C (2007) Gamma glutamyl transferase and long-term survival: is it just the liver? Clin Chem 53:940-946

Kensler TW, Wakabavashi N (2010) Nrf2: friend or foe for chemoprevention? Carcinogenesis 31:90-99

Khalil A, Kabapy N, Deraz S, Smith C (2011) HSP in oncology: diagnostic biomarkers or therapeutic target? Biochim Biophys Acta 1816:89-104

Laemmli UK (1970) Cleavage of structural proteins during the assembly of the head of bacteriophage T4. Nature 227:680-685

Malik S, Bhatnagar S, Chaudhary N, Katare DP, Jain SK (2013) DEN + 2-AAF-induced multistep hepatotumorigenesis in Wistar rats: supportive evidence and insights. Protoplasma 250:175-183

Moreira A, Rodrigues G, Bona S, Cerski T, Marroni C, Muriz J, Gonzalez Gallego J, Marroni N (2015) Oxidative stress and cell damage in a model of precancerous lesions and advanced hepatocellular carcinoma in rats. Toxic Rep 2:333-340

Pandur S, Pankiv S, Johannessen M, Moens U, Huseby NE (2007) Gamma-glutamyl transferase is upregulated after oxidative stress through the Ras signal transduction pathway in rat colon carcinoma cells. Free Radic Res 41:1376-1384

Paolicchi A, Pompella A, Tonarelli P, Gadducci A, Genazzani AR, Zunino F, Pratesi G et al (1996) Gamma glutamyl transpeptidase activity in human ovarian carcinoma. Anticancer Res 16(5B): 3053-3058

Poirier L (2002) The effects of diet, genetics and chemicals on toxicity and aberrant DNA methylation: an introduction. J Nutr 132:2336S-2339S

Pompella A, De Tata V, Paolicchi A, Zunino F (2006) Expression of gamma-glutamyltransferase in cancer cells and its significance in drug resistance. Biochem Pharmcol 71(3):231-238

Roomi MW, Lee G, Faber E (1987) Expression of serum and hepatic $\gamma$-glutamyl transferase $(\gamma$-GT) activities during carcinogenic process in resistant hepatocyte (R-H) model in rat. Clin Biochem V 20(4):296

Roskams TA, Theise ND, Balabaud C, Bhagat G, Bhathal PS, Bioulac-Sage P, Brunt EM, Crawford JM, Crosby HA, Desmet V, Finegold MJ, Geller SA, Gouw AS, Hytiroglou P, Knisely AS, Kojiro M, Lefkowitch JH, Nakanuma Y, Olynyk JK, Park YN, Portmann B, Saxena R, Scheuer PJ, Strain AJ, Thung SN, Wanless IR, West AB (2004) Nomenclature of the finer branches of the biliary tree: canals, ductules, and ductular reactions in human livers. Hepatology 39(6):1739-1745

Sang W, Zhang W, Cui W, Li X, Abulajiang G, Li Q (2015) Arginase-1 is a more sensitive marker than HepPar-1 and AFP in differential diagnosis of hepatocellular carcinoma from nonhepatocellular carcinoma. Tumor Biol 36:3881-3886

Santos NP, Oliveira PA, Arnates-Rodrigues R, Faustino-Rocha AI, Colaço A, Lopes C, Gil da Costa RM (2014) Cytokeratin 7/19 expression in N-diethylnitrosamine induced mouse hepatocellular lesions: implications for histogenesis. Int J Exp Pathol 95:191-198

Shafizadeh N, Kakar S (2011) Diagnosis of well-differentiated hepatocellular lesions: role of immunohistochemistry and other ancillary techniques. Adv Anat Pathol 18:438-445

Song P, Inagaki Y, Wang Z, Hasegawa K, Sakamoto Y, Arita J, Tang W, Kokudo N, Song P, Inagaki Y, Wang Z, Hasegawa K, Sakamoto Y, Arita J, Tang W, Kokudo N (2015) High levels of gamma-glutamyl transferase and indocyanine green retention rate at $15 \mathrm{~min}$ as preoperative predictors of tumor recurrence in patients with hepatocellular carcinoma. Medicine 94(21):e810

Souza A, Meurer L, Silveira TR, Gregorio C, Reus N, Uribe C, Matte U et al (2014) Angiopoietin 1 and angiopoietin 2 are associated with medial thickening of hepatic arterial branches in biliary atresia. Pediatr Res 75:22-28

Sporn MB, Liby KT (2012) NRF2 and cancer: the good, the bad and the importance of context. Nat Rev Cancer 12:564-571

Srinivasan V, Spence DW, Pandi-Perumal SR, Trakht I, Cardinali DP (2008) Therapeutic actions of melatonin in cancer: possible mechanisms. Integr Cancer Ther 7:189-203

Tang $\mathrm{CH}$ et al (2013) Hepatocarcinogenesis driven by GSNOR deficiency is prevented by iNOS inhibition. Cancer Res 73:2897-2904

Thoolen B, Kate FJW, Diest PJ, Malarkey DE, Elmore SA, Maronpot RR (2012) Comparative histomorphological review of rat and human hepatocellular proliferative lesions. J Toxicol Pathol 25: 189-199

Tice RR, Agurell E, Anderson D, Burlinson B, Hartmann A, Kobayashi H, Miyamae Y et al (2000) Single cell gel/comet assay: guidelines for in vitro and in vivo genetic toxicology testing. Environ Mol Mutagen 35:206-221

Tuñón MJ, San-Miguel B, Crespo I, Laliena A, Vallejo D, Alvarez M, Prieto J et al (2013) Melatonin treatment reduces endoplasmic reticulum stress and modulates the unfolded protein response in rabbits with lethal fulminant hepatitis of viral origin. J Pineal Res 55:221-228

Van Eyken PL, Sciot R, Paterson A, Callea F, Kew MC, Desmet VJ (1988) Cytokeratin expression in hepatocellular carcinoma: an immunohistochemical study. Hum Pathol 19:562-568

Verna L, Whysner J, Williams GM (1996) N-Nitrosodiethylamine mechanistic data and risk assessment: bioactivation, DNAadduct formation mutagenicity and tumor initiation. Pharmacol Ther 71:57-81

Vydra N, Toma A, Widlak W (2014) Pleiotropic role of HSF1 in neoplastic transformation. Curr Cancer Drug Targets 14:144-155

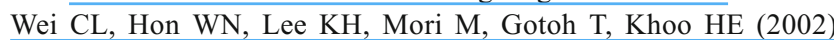
Induction of arginase II in livers of bile duct ligated rats. Biochem Pharmacol 63:1043-1050

Whitfield JB (2001) Gamma-glutamyltransferase. Crit Rev Clin Lab Sci 38:263-355

Williams GM, Iatropoulos MJ, Wang CX, Ali N, Rivenson A, Peterson LA, Schulz C et al (1996) Diethylnitrosamine exposure-responses for DNA damage, centrilobular cytotoxicity, cell proliferation and carcinogenesis in rat liver exhibit some non-linearities. Carcinogenesis 17:2253-2258

Wong CM, Ng IOL (2008) Molecular pathogenesis of hepatocellular carcinoma. Liver Int 28:160-174

Yang Z, Ye P, Xu Q, Lu Y, Tang B, Wang Q, Chen S, Chen X (2015) Elevation of serum GGT and LDH levels, together with higher BCLC staging are associated with poor overall survival from hepatocellular carcinoma: a retrospective analysis. Discov Med 19(107): 409-418

Ye F, Jing Y, Guo SW, Yu GF, Fan QM, Qu FF, Gao L, Yang Y, Wu D, Meng Y, Yu FH, We LX (2014) Proliferative ductular reactions correlate with hepatic progenitor cell and predict recurrence in HCC patients after curative resection. Cell Biosci 4:50 
Zhang H, Liu H, Iles KE, Liu RM, Postlethwait EM, Laperche Y, Forman HJ (2006) 4-Hydroxynonenal induces rat gammaglutamyl transpeptidase through mitogen-activated protein kinase-mediated electrophile response element/nuclear factor erythroid 2-related factor 2 signaling. Am J Respir Cell Mol Biol 34(2):174-181

Zhang JB, Chen Y, Zhang B, Xie X, Zhang L, Ge N, Ren Z, Ye SL (2011) Prognostic significance of serum gamma-glutamyl transferase in patients with intermediate hepatocellular carcinoma treated with transcatheter arterial chemoembolization. Eur J Gastroenterol Hepatol 23:787-793

Zhang Q, Ma Z, Xin Q, Liu GQ, Liu BB, Gao YT, Zhang CS, Du Z (2013) Diagnostic value of absent ductular reaction at hepatocellular-stromal boundaries in early stage hepatocellular carcinoma. Zhonghua Gan Zang Bing Za Zhi 21(12):924-928 